\title{
Desenho da rede de um projeto esportivo social: atores, representações e significados
}

CDD. 20.ed. 796

796.05

http://dx.doi.org/10.1590/1807-55092014000300415
Orestes Manoel da SILVA* Carlos Alberto Figueiredo da SILVA ${ }^{* * *}$
*Universidade Salgado de Oliveira.

${ }^{* *}$ Centro Universitário Augusto Motta.

\section{Resumo}

Este estudo é oferecido com o objetivo de explorar os sentidos e significados atribuídos pelos atores de uma rede que desenvolve um projeto esportivo social. 0 Projeto Boxe Vidigal (PBV) tem suas atividades no morro do Vidigal, localizado na zona sul da cidade do Rio de Janeiro, ao lado do bairro do Leblon. A metodologia utilizada no estudo pautou-se pelos procedimentos da análise de redes e também da construção de categorias, com base na definição do núcleo e da periferia de representações sociais. Conclui-se que existe grande centralização das ações na pessoa do idealizador do projeto, por esta razão há baixa densidade e alta centralidade na rede. As percepções dos atores circulam pelas ideias de que o projeto "muda a vida das pessoas", que os jovens "tornam-se menos agressivos", que há "contribuição na formação social das crianças, jovens e das famílias" e que promove a "inclusão social de pessoas que vivem em comunidades pobres".

Palavras-chave: Projeto esportivo social; Educação física; Criança; Esporte.

\section{Introdução}

Políticas esportivas para crianças e adolescentes têm sido objetivos de organismos públicos, privados e do terceiro setor no Brasil ${ }^{1-3}$. Por meio de diferentes iniciativas, surgem em todo o país inúmeros projetos com o intuito de promover atividades esportivas. Essas iniciativas, nomeadas em sua maioria pelo termo projetos esportivos sociais, vêm ganhando destaque na mídia e na sociedade ${ }^{3-4}$.

Para uma melhor compreensão de tais iniciativas, torna-se necessário investigar tanto o que tem sido proposto como o que tem sido buscado pelos participantes desses projetos.

No âmbito dos projetos esportivos sociais, as açôes que têm se disseminado na sociedade vêm se consolidando num movimento de baixo para cima. Esses projetos são constituídos, muitas vezes, a partir de açôes de indivíduos, grupos e organizaçóes que se mobilizam em torno de um objetivo comum. $\mathrm{O}$ movimento inverso, de cima para baixo, a participação direcionada da esfera governamental, também se faz presente. Entretanto, o volume de açôes que vêm ocorrendo de baixo para cima no Brasil, configura-se como um fenômeno típico do final do século XX e início do século XXI, que merece a atenção da academia ${ }^{5-6}$. Nesse caminho, Boaventura SANTOS ${ }^{7}$ diz que:

[...] é útil distinguir entre globalização de-cimapara-baixo e globalização de-baixo-para-cima (...). A complexidade dos direitos humanos reside em que eles podem ser concebidos, quer como forma de localismo globalizado, quer como forma de cosmopolitismo ou, por outras palavras, quer como globalização hegemônica, quer como globalização contra-hegemônica (...). A minha tese é que, enquanto forem concebidos como direitos humanos universais, os direitos humanos tenderão a operar como localismo globalizado - uma forma de globalização decima-para-baixo. Serão sempre um instrumento do "choque de civilizaçōes" (...). Para poderem operar como forma de cosmopolitismo, como globalização de-baixo-para-cima ou contrahegemônica, os direitos humanos têm de ser reconceptualizados como multiculturais (p.111).

Este trabalho tem como objeto de estudo o projeto denominado Boxe Vidigal. O Projeto Boxe Vidigal (PBV) utiliza a modalidade boxe para a inclusão social de crianças e adolescentes da comunidade. 
O PBV começou a ser organizado no ano de 1999. É coordenado pelo professor Raff Giglio e desenvolvido na Avenida Niemeyer, Vidigal, cidade do Rio de Janeiro.

Devido à sua localização, o bairro do Vidigal se constitui numa das mais importantes favelas do Rio de Janeiro. Situado ao longo da Avenida Niemeyer, fica entre os bairros de São Conrado e Leblon, nas encostas do morro Dois Irmãos. Possui uma vista privilegiada, pois é voltado diretamente para o mar e para os bairros de São Conrado, Leblon e Ipanema, exibindo um forte contraste entre a riqueza e a pobreza.

A história da Comunidade do Vidigal se inicia com a ocupação do morro em 1941, com os primeiros barracos sendo construídos abaixo da Avenida Niemeyer até a praia do Vidigal. No início da década de 50, os moradores foram removidos para a parte situada acima da avenida e sua explosão demográfica aconteceu nas décadas de 50 e 60, devido à urbanizaçáo dos bairros do Leblon e de Ipanema.

Na entrada principal da comunidade está o Colégio Stella Maris, que nos anos 1960 era destinado à educação da classe média alta da cidade, mas, com o crescimento da favela, tornou-se um colégio filantrópico para a educação da comunidade de baixa renda.

Em 1967, foi criada a Associação de Moradores do Vidigal, e em 1968 teve início a construção do Hotel Sheraton, cuja companhia que o administrava tentou privatizar a pequena praia localizada embaixo do local onde está o hotel, porém os moradores ganharam na justiça o direito de frequentá-la.

No final dos anos 1970, com a política de remoção das favelas criada pelos governos militares, tentou-se, sem sucesso, a eliminação da favela do Vidigal, objetivando liberar o terreno para dar lugar à construção de empreendimentos de alto luxo. Após intensa luta, os moradores conseguiram apoio político e popular, e em 1978 foi editado o decreto de desapropriação da área para fins sociais, assinado pelo governador Chagas Freitas, banindo de vez o perigo da remoção.

$\mathrm{Na}$ década de 80, assim como em outras favelas da cidade, o Vidigal sofreu a invasão do tráfico de drogas, através da instalação da facção criminosa Comando Vermelho, que, impondo sua ordem, obrigou os moradores a viver sob a sua tutela.

A palavra comunidade, por si só, já nos remete a significados pejorativos. Tratar de questôes referentes à pobreza humana, especialmente em comunidades cariocas, é um tanto complexo. Estas áreas circulam na imaginação social como um ambiente misterioso.

Além disso, a mídia e o senso comum mantêm uma imagem negativa acerca das comunidades, sendo corriqueiro relacioná-las à violência, criminalidade e pobreza.

É fato que esses locais são desprovidos de aparatos urbanos, sua infraestrutura é precária e frequentemente é palco de conflitos. Contudo, não podemos associar esta população à violência, e limitar a questão.

Atualmente as comunidades do Rio de Janeiro ganharam visibilidade, mas ainda predomina a visão negativa. Mesmo com os debates acerca da pobreza e exclusão estarem em evidência, confusóes em relação a estes conceitos são comuns.

Entendemos que existem níveis e graus de exclusão diferentes. A exclusão a qual nos referimos é aquela onde cidadãos estão desprovidos de bens e serviços, sem condiçóes de moradias adequadas e que disputam em condiçóes desiguais de oportunidades, sendo facilmente encontrados nas comunidades do Rio de Janeiro.

A exclusão como revelação de injustiça se manifesta quando pessoas são continuamente excluídas dos serviços, benefícios e garantias oferecidos pelo Estado, entendidos, geralmente, como direitos do cidadão ${ }^{8}$.

Com cunho social e esportivo, e o objetivo de desenvolver os aspectos físicos, morais e sociais das crianças e adolescentes da comunidade, o Projeto Boxe Vidigal, na visão de seu idealizador, busca trazer noçóes de cidadania e expectativa de profissão futura para que seus alunos se transformem em adultos participantes, responsáveis e produtivos.

Ao acompanhar o processo de multiplicação de projetos esportivos sociais, verifica-se que há um crescente interesse de autores da educação física e de outras áreas. Esses estudos têm objetivado analisar os discursos dos gestores e educadores, havendo uma carência de diálogo com o público-alvo?

O sonho de ascensão profissional através do esporte é mais forte nos mais pobres. O esporte funciona como agente de socializaçáo e de alargamento das redes de sociabilidade ${ }^{8}$.

O esporte ganhou no senso comum uma imagem de passaporte para a ascensão social ${ }^{10}$. Seja por influência da mídia, onde há uma divulgação de histórias de jogadores famosos que saíram de classes inferiores, de boxeadores que conquistaram fama internacional ou até mesmo de projetos sociais, algumas crianças e adolescentes pobres têm no esporte uma possibilidade de escapar da pobreza.

Este estudo tem como objetivo geral analisar a rede que está a se construir no PBV, a partir das representaçóes de seus atores. Como desdobramento do objetivo principal, foram formulados os seguintes 
objetivos específicos: a) analisar as características da rede construída no PBV; b) interpretar as representaçóes de membros da rede sobre os sentidos e significados atribuídos ao projeto na comunidade do Vidigal.

O objeto rede social tem se tornado cada vez mais operativo para os estudos das sociedades contemporâneas, vindo ao encontro de uma exigência de complexificação da teoria social a partir de demandas práticas, configurando-se num fenômeno não apenas funcional, mas de análise da nova ordem social.

Num país em desenvolvimento como o Brasil, as açóes que incentivem e alavanquem a melhora da autoestima e da motivação em comunidades que apresentam vulnerabilidade social, colabora, substancialmente, para que a inclusão social ocorra de forma efetiva ${ }^{11}$. Quando uma rede se organiza para projetar o desenvolvimento de uma regiáo, a probabilidade de sucesso é maior.

A intenção deste trabalho é mostrar, além das representaçóes de gestores e educadores, a perspectiva de alunos e atletas, essencialmente o público alvo do projeto, e desta forma, adentrar num espaço, que necessita ser mais bem conhecido.

Esporte e redes de desenvolvimento social

O esporte é apresentado como um direito constitucionalmente assegurado, porém, a população carece de locais com profissionais para dirigir e ensinar as práticas esportivas ${ }^{12}$. Por isso, a necessidade de disseminação do esporte e de seus valores através de políticas públicas esportivas.

A relação entre o esporte e as comunidades de baixa renda é notória. Os trabalhos esportivos realizados nessas comunidades têm obtido resultados significativos na administração dos índices de violência social. Tais iniciativas esportivas são aceitas por todos os organismos internacionais reconhecidos ${ }^{13}$.

As redes sociais influenciam o comportamento de indivíduos e grupos, e a ação humana é afetada pelas relaçốes sociais em que os atores estão submersos ${ }^{14}$. As interaçôes sociais aprimoram ou reduzem o acesso a recursos; pois, reunindo um capital social, geram-se três externalidades: o conhecimento sobre o comportamento dos outros agentes, o conhecimento sobre o mercado e o benefício da ação coletiva ${ }^{15}$.

Desta forma, a construçáo de uma base inicial de recursos representa um grande desafio para o idealizador de projetos esportivos sociais. O método pelo qual uma ideia se torna realidade palpável distingue-se pela existência de barreiras e diversas tentativas, reunindo estudos nas atividades iniciais e de crescimento, valorizando a importância de recursos básicos como dinheiro, pessoas e informações, que devem ser obtidos para começar o empreendimento.

É importante ressaltar que o empreendedor é o primeiro recurso e seus objetivos sobre o futuro do empreendimento são fundamentais para a direção estratégica e sua sobrevivência.

\section{Conceito e análise de redes}

Há uma grande variedade de definiçóes para redes, no entanto, todas convergem para o sentido de ligação, laço e interação. A noção de redes, no campo da teoria da complexidade, caracteriza-se por uma integração de elementos diversos, cujo fluxo de movimentos potencializa a sinergia coletiva por meio de relaçóes que esses elementos mantêm entre si e também com elementos externos ${ }^{16}$.

O conceito de redes é oriundo de polaridades existentes nas ciências sociais, geradas a partir de conflitos e correntes que criam pares dicotômicos: indivíduo/sociedade, ator/estrutura, enfoque micro/ macro, subjetividade/objetividade ${ }^{17}$.

Diante desses determinismos institucionais, as redes surgiriam como um novo instrumento para análise de movimentos sociais. A percepção de que as redes são ferramentas organizacionais e se constituem como objeto de estudo para compreender tanto a mudança como a estrutura social ganhou força nas últimas décadas. A literatura mostra que o trabalho das pessoas por meio de conexóes em rede é tão antigo como a história da humanidade. Entretanto, a inovação está em reconhecer e valorizar a experiência individual na configuração da perspectiva global. De acordo com LIPNACK e STAMPs ${ }^{18}$ :

O que é novo no trabalho em redes de conexões é a sua promessa como uma forma global de organização com raízes na participação individual. Uma forma que reconhece a independência enquanto apoia a interdependência. $\mathrm{O}$ trabalho em redes de conexões pode conduzir a uma perspectiva global baseada na experiência pessoal (p.19).

A compreensão e os métodos de análise dessas redes têm sido muito utilizados na comunidade científica para avaliar relacionamentos entre entidades sociais, padrôes, e implicaçóes desses relacionamentos ${ }^{19-20}$.

A análise de redes observa a coleção de atores ou indivíduos e as interaçóes que ocorrem. Uma listagem com conceitos das principais características de uma rede social foi elaborada, a saber: ator ou nó (indivíduos que participam da rede); blocos de segmentação (conjunto de atores); centralidade 
de Bonacich (medida qualitativa que se refere ao prestígio de um ator em uma rede); centralidade de entrada (número de pessoas que citaram um determinado ator); centralidade de saída (número de pessoas que um determinado ator citou); grau de intermediaçáo (mede o controle que um ator deve ter para manter a interaçáo entre dois ou mais atores); grau de proximidade (número mínimo que um ator necessita para interagir com qualquer ator na mesma rede; centralidade (identificação da posição de um ator em relação às interaçóes na rede); clique (subgrupo com dois ou mais nós. Os conceitos ncliques, n-clâns e k-plexes são derivações dos cliques); conector central ou ponto de corte (responsável por ligar a maior parte dos atores uns aos outros e por fornecer as informaçôes necessárias para a dinâmica do trabalho, caso este ator seja retirado, levará consigo um ou mais conjuntos de pessoas); densidade (quociente entre a quantidade de ligaçôes existentes por quantidade de ligaçóes possíveis em uma rede); diâmetro (maior distância geodésica entre pares de atores de uma rede); distância geodésica (número mínimo de relações que separam dois atores quaisquer na rede, ou seja, é o caminho mais curto entre dois atores de uma rede); especialista periférico (ator que os outros integrantes recorrem quando precisam de algum tipo de apoio, informaçáo e reconhecimento); grupo (quando um conjunto de atores possui ligaçóes finitas); laço ou elo (ligação entre o par de atores); nó isolado (ator que não colabora com o sistema de troca); reciprocidade (relaçóes que fluem nos dois sentidos); relação (tipo de conteúdo trocado em um laço); tamanho (número de ligaçôes entre os atores de uma determinada rede $)^{21-22}$.

Pode-se realizar a análise das redes sociais tomando-se como foco duas abordagens do mesmo fenômeno, sendo que a primeira é a abordagem estrutural e a segunda redes centradas em egos ${ }^{21}$.

A abordagem estrutural pode ser subdividida em duas dimensóes: Macro - medidas referentes a tamanho, densidade, distâncias geodésicas e diâmetro na estrutura da rede; e Micro - onde se avaliam a coesão, os subgrupos denominados de cliques, a posição dos atores e sua equivalência estrutural.

A abordagem das redes centradas em egos é um zoom sobre os atores. Neste caso, o ator se torna o alvo da atenção. A função do ator na manutenção, expansão ou mesmo quebra nos fluxos de ligaçôes, formando relaçóes de poder e influência, passa a ser mais visualizada nessa abordagem, onde se destaca o conceito de centralidade ou prestígio para a compreensão das redes ${ }^{23}$.
O conceito de centralidade facilita a compreensão das redes, pois identifica e localiza os atores mais responsáveis pelo movimento das mesmas, visto que ocupam posiçôes estratégicas na estrutura informal ${ }^{24}$.

O conceito de centralidade demonstra o quanto um ator está acessível para os demais atores da rede. A posição em que o ator está em relação às trocas avaliadas pode ser visualizada em quatro tipos básicos de centralidade ${ }^{21}$.

A centralidade pode ser de grau, proximidade, intermediação e Bonacich. A centralidade de grau observa o número de ligaçóes que um ator recebe, denotando popularidade ou receptividade (centralidade de entrada) e também o número de ligaçóes que um ator estabelece com outros atores da rede, denotando expansividade (centralidade de saída) ${ }^{25}$.

A centralidade de proximidade é baseada na distância de um ator para outro, obtêm-se a partir da soma das distâncias geodésicas.

A centralidade de intermediação baseia-se no potencial controle de um ator sobre a interação entre dois outros, denotando capacidade de interrupção.

A centralidade de Bonacich observa o número de ligaçóes diretas que um ator possui dentro da rede, mas também a centralidade dos atores adjacentes. Esta centralidade denota um aspecto de prestígio global ${ }^{25}$.

O conceito de redes implica uma proposta de açáo. A literatura, num certo sentido, relaciona à noçáo de redes as ideias de modo espontâneo de organização em oposição a uma dimensão formal e instituída ${ }^{26}$; parceria voluntária, objetivo comum, coletividade, liberdade e identidade ${ }^{27}$. No entanto, as redes podem ser mais ou menos formais, e até mesmo informais, dependendo de sua tipologia.

Identificam-se quatro tipos de redes: a primeira é relativa ao campo das Relaçôes Interpessoais; a segunda, ao campo dos Movimentos Sociais; a terceira, relativas ao Estado (Estados/Políticas Públicas) e a quarta ao campo dos Negócios (Produção/Circulação). Relativamente, a informalidade/formalidade das redes se configura em funçáo do seu tipo. À relativa ao campo das Relaçôes Interpessoais e dos Movimentos Sociais tem a prevalência da informalidade sobre a formalidade. Esta lógica se inverte nas relativas ao Estado e ao campo da Produção/Circulaçãa ${ }^{28}$.

O primeiro tipo de rede identificado, no campo interpessoal, tem como atores os indivíduos e é caracterizada pela informalidade, interesses e valores comuns, troca/ajuda mútua, confiança/ cumplicidade, interações horizontais, mudanças/ flutuaçôes, engajamento voluntário, racionalidade comunicativa sobrepondo-se à instrumental. 
No campo Interpessoal, a informalidade é uma característica marcante, mas ao se observar o campo Produção/Circulação, há prevalência da formalidade. Observa-se, também, que nos campos Interpessoal e dos Movimentos Sociais a racionalidade comunicativa (substantiva), que focaliza os valores, os fins, a razão de ser, tem prevalência em relação à racionalidade instrumental. Já nos campos Estados/Políticas Públicas e Produção/Circulação, a prevalência é da racionalidade instrumental, que focaliza o resultado, o custo/benefício, a técnica.

Há quem oponha as redes informais às formais. A primeira refere-se a um conjunto de interaçóes espontâneas passíveis de descrição num dado momento, que aparecem num contexto definido pela presença de certas práticas mais ou menos formalizadas; já a rede formal refere-se ao propósito de organizar essas interaçóes de um modo mais explícito, traçando-lhes uma fronteira ou limite, conferindo-lhes um nome e gerando, assim, um novo nível de complexidade, uma nova dimensão ${ }^{29}$.

Redes formais podem surgir a partir de relaçóes entre universidade, indústria e governo, por exemplo, quando uma universidade desenvolve açóes de

\section{Método}

A metodologia utilizada neste trabalho foi de cunho exploratório e priorizou uma abordagem qualitativa, não obstante ter lançado mão de análises estatísticas. O objeto de estudo, o Projeto Boxe Vidigal (PBV), foi construído com o apoio de dois referenciais teórico-metodológicos.

O primeiro ancorado em princípios da análise de redes, tomando como base a abordagem estrutural na dimensão macro, onde se observa, principalmente, tamanho, densidade, centralidade e tipo de rede ${ }^{21-31}$.

O segundo, alicerçado na teoria das representaçôes sociais ${ }^{32-35}$, visou, principalmente, identificar o núcleo e a periferia das representaçóes por meio de entrevistas semiestruturadas e da técnica do grupo focal.

O objeto de estudo foi observado em seu ambiente natural, de modo a dar sentido ou interpretar fenômenos em termos dos significados que as pessoas lhes trazem ${ }^{36}$.

A observação se fez pelo interior, sob o ponto de vista dos participantes e dos profissionais que atuam diretamente no trabalho da rede. $O$ potencial dessa perspectiva provém da coerência da estrutura pesquisa e desenvolvimento em colaboração com indústrias, tendo fomento governamental.

Em vários países, inclusive no Brasil, a parceria entre público e privado vem se constituindo em uma alternativa de crescimento para determinados setores. Quando a universidade faz parte da rede, a perspectiva crítica introduz elementos reflexivos sobre o papel da rede e sua função social.

No caso brasileiro as universidades focalizam não só o empreendedorismo empresarial, os objetivos sociais e os projetos de empreendedorismo têm se destinado também à inclusão social. Os valores são fundamentais para que as instituiçóes tomem este ou aquele caminho. A formação de redes de desenvolvimento, por exemplo, no Reino Unido, tem uma forte ênfase na criação de riqueza, mas, esta é apenas uma direçáo para o desenvolvimento acadêmico. As universidades podem ter metas simultâneas de negócios e desenvolvimento social, como no Brasil ${ }^{30}$.

Os campos Interpessoal e de Movimentos Sociais, têm se caracterizado pela valorização de elos informais e das relaçóes, em detrimento das estruturas hierárquicas. $\mathrm{O}$ trabalho informal em rede é hoje uma forma de organização humana em expansão ${ }^{17}$.

das relaçóes entre da coerência das variações dessas relaçôes no tempo ${ }^{37}$.

Utilizou-se o "software" Ucinet for Windows 6: Software for Social Network Analysis ${ }^{31}$ para analisar o desenho da rede, o grau de centralidade, a densidade, os graus de entrada e de saída dos atores, fatores relacionados a um tipo de análise macroestrutural da rede.

O critério de seleção do "lócus" da pesquisa se justifica pelo fato de o projeto existir desde 1999 e apresentar-se consolidado na comunidade, o que permitiu a observação sistemática por parte dos pesquisadores.

Os sujeitos participantes foram: o idealizador do projeto, instrutores, alunos, atletas, dois colaboradores, todos membros da rede. A amostra foi intencional $^{38}$, com os seguintes critérios: o idealizador do projeto foi escolhido em virtude de sua importância na rede; os alunos, atletas e instrutores por fazerem parte de um grupo com alto grau de centralidade e os colaboradores por fazerem parte de um subgrupo com baixo grau de centralidade. De forma a esclarecer melhor estes critérios, o primeiro grupo, com alto grau de centralidade, implica relaçáo de reciprocidade, ou seja, as relações desses atores fluem nos dois sentidos, 
com alto grau de centralidade de entrada e de saída (FIGURA 1). No caso dos colaboradores, não há relaçóes de reciprocidade com o primeiro grupo, e um baixo grau de centralidade (FIGURA 1).

Os instrumentos de coleta de dados constituíramse de entrevistas semiestruturadas, que foram realizadas individualmente (no caso dos colaboradores) e com a metodologia do grupo focal (no caso dos alunos, atletas e instrutores).

As entrevistas semiestruturadas seguiram um roteiro com o intuito de oferecer aos entrevistados a possibilidade de compartilhar e dissertar sobre o tema selecionado, e a possibilidade de acrescentar novas perguntas no decorrer do diálogo ${ }^{38-41}$. O roteiro para o idealizador do projeto deixou-o livre para falar da gênese do $\mathrm{PBV}$, de seus parceiros, colaboradores e objetivos a serem alcançados.

O roteiro para o grupo focal com os alunos e atletas focalizou as seguintes questóes: o boxe faz com que você se sinta mais incluído dentro do seu círculo social? Com a prática do boxe, o que acredita que mudou ou pode mudar na sua vida? Você acredita que o seu comportamento em casa e com os familiares mudou com o boxe? Você se sente mais ou menos agressivo depois que começou a praticar boxe? O que representa o PBV para você? O que é cidadania para você? O PBV contribui com a sua formação de cidadáo? Como? Como o projeto contribui para a sua formação educacional? Os seus pais conhecem o projeto? E o que eles acham? Você tem alguma referência na sua vida? Dentro ou fora do projeto? Qual? O que você espera para a sua vida e como pretende alcançar os seus objetivos?

O roteiro para os instrutores observou as seguintes questôes: o projeto incentiva a participação de seus alunos em projetos ou atividades sociais? Como você se tornou instrutor? Você relaciona o boxe como uma possível fonte de renda para os seus alunos? De que forma? Esta visão é diferente da que você tinha antes de ser instrutor do projeto? Como o boxe afeta o rendimento escolar dos alunos? Com a prática do boxe, o que acredita que mudou ou pode mudar na vida de seus alunos? Você acredita que o comportamento de seus alunos em casa e com os familiares mudou com o boxe? Você acha que os alunos se tornaram mais ou menos agressivo depois que começou a praticar boxe? Você vê alguma diferença ou pontos em comum entre você e outros instrutores do projeto?

$\mathrm{O}$ roteiro para os colaboradores focalizou as seguintes questôes: como conheceu o PBV? Como você contribui para o projeto? Existe algum tipo de retorno com a sua contribuição? Você conhece os objetivos do projeto? Como o boxe pode interferir na qualidade de vida dos alunos e de suas famílias? Você acredita que o projeto minimiza a influência do tráfico de drogas nos jovens da comunidade? Qual a contribuição do projeto para a cidadania? Como você observa o reflexo do projeto na comunidade?

A análise dos dados foi organizada de forma a verificar o núcleo das respostas, aquilo que foi destacado pelo grupo ou pelo entrevistado e também o que apareceu como periférico ${ }^{32-34}$. Desta forma, as ideias que se consolidavam em função de uma centralização, ratificação, ilustração realizadas pelo grupo ou pelo entrevistado, compuseram o núcleo. Em relação ao núcleo de uma representação, ABRIC ${ }^{32}$ nos ilumina ao dizer que:

A simples identificação do conteúdo de uma representação não basta para o seu reconhecimento e especificação. A organização deste conteúdo é essencial: duas representaçōes definidas por um mesmo conteúdo podem ser radicalmente diferentes, caso a organização destes elementos, portanto, sua centralidade, seja diferente (p.31).

Abric nos remete, entáo, à perspectiva de organização das representaçóes durante o processo interativo das entrevistas. O núcleo foi organizado de forma interativa entre os participantes das entrevistas e o pesquisador.

Em relação às representaçóes que não compóem o núcleo, consideramo-las como representaçóes periféricas em função de não terem tido, à época do processo interativo das entrevistas, a necessária saturação, destaque e reforço por parte do grupo ou do entrevistado. Assim, a ideia que surgiu durante a entrevista, mas não foi desenvolvida, ficou categorizada como periferia. Há também uma periferia distante, que, neste estudo, denominamos como formas incidentais. Ideias que aparecem sem referência ao que estava em processo de construção no momento da entrevista e que acabavam por ficar isoladas no discurso.

Os pesquisadores disponibilizaram tempo prolongado no local para que pudessem desenvolver a compreensão das atividades, a descrição do ambiente e o contexto. Por fim, foi utilizado o critério de checagem pelos participantes, houve um retorno ao campo da investigaçáo, de modo que os participantes tivessem acesso à transcrição e análise das entrevistas.

Os aspectos éticos para a pesquisa consistiram em: aprovação pelo comitê de ética em pesquisa da Universidade Salgado de Oliveira, parecer $n^{\circ}$ 93/2010; preenchimento do Termo de Consentimento Livre e Esclarecido (TCLE), que garante o comprometimento do pesquisador para com as pessoas envolvidas no estudo. 


\section{Resultados}

Nesta parte são apresentados os dados coletados por meio de entrevistas e das observaçóes. O nosso contato com o PBV teve início em 2010, quando realizamos entrevistas, participamos de aulas práticas e reuniōes com instrutores e coordenação. Os contatos iniciais visaram proporcionar o comprometimento da coordenaçáo do PBV no desenvolvimento de uma pesquisa participativa.

A receptividade para a realizaçáo do estudo foi muito boa, e o idealizador/coordenador aceitou a proposta de abordagem apresentada, identificando a importância do estudo para o desenvolvimento do PBV.

\section{Entrevista com o idealizador/coordenador do PBV}

Apresentamos os principais pontos desenvolvidos por Raff Giglio durante a entrevista que nos concedeu sobre a constituição do PBV.

\section{Origem do projeto}

O PBV começou a ser organizado no ano de 1999. O idealizador do PBV, Raff Gigglio, vislumbrou um espaço no bairro do Vidigal para iniciar um projeto de boxe. Seu relato afirma que teve de vender tudo o que possuía para iniciar as atividades da academia. O grande impulso deu-se a partir de uma visita do campeáo mundial de boxe, o baiano Acelino "Popó" Freitas, que proferiu palestras aos primeiros alunos.

$\mathrm{Na}$ organização das atividades, três equipes foram definidas e nomeadas como Equipes A, B e C.

Equipe A: formada por alunos que já participam de competiçóes; Equipe B: conta com os alunos que estão se preparando para competir; Equipe C: contempla os alunos que estáo iniciando no esporte.

\section{Patrocínio}

O principal patrocinador é a distribuidora de material médico-hospitalar Oscar Iskin. Além desta, o projeto conta também com o incentivo do Ministério do Esporte, que concede bolsa atleta aos competidores nacionais e internacionais que conquistam medalhas. Existem também voluntários que contribuem com cestas básicas, passagens aéreas e rodoviárias, para que a equipe participe em competições.

\section{Desenho da rede}

Esta rede é composta pelos seguintes atores: Raff Giglio (idealizador e coordenador do projeto), Atletas (alunos em fase avançada que já participam de competiçôes), Alunos (considerados aqueles em fase de iniciação ao boxe), Funcionários, Colaboradores Pessoas Jurídicas (empresas que fazem doaçôes ao projeto), Instrutores (responsáveis pelas atividades de aprendizagem do boxe), Federação de Boxe (instituição em nível estadual), Confederação de Boxe (instituição em nível federal), Ministério do Esporte, Senhora das Bolsas (voluntária que concede alimentação, nomeada assim pelos participantes por trazer a comida em várias bolsas), Empresa Hospitalar (pessoa jurídica cujo proprietário é grande amigo de Raff Giglio e apresenta relação de reciprocidade com o PBV), Popó (Acelino Freitas, campeão de boxe e amigo de Raff Giglio), Condomínio (local que abrigou o projeto por um longo tempo), Ator de Televisão (voluntário, amigo de Raff Giglio, que faz doações para que os atletas participem de competiçóes), Colaboradores Pessoas Físicas (outros voluntários), Associação de Moradores (do Vidigal, apoia o desenvolvimento do projeto na comunidade), Emissora de Televisão (rede de televisão de grande penetraçáo no Brasil, que mantém relação estreita com Raff Giglio).

A FIGURA 1 apresenta o desenho gráfico da rede desenvolvida em torno do projeto. 


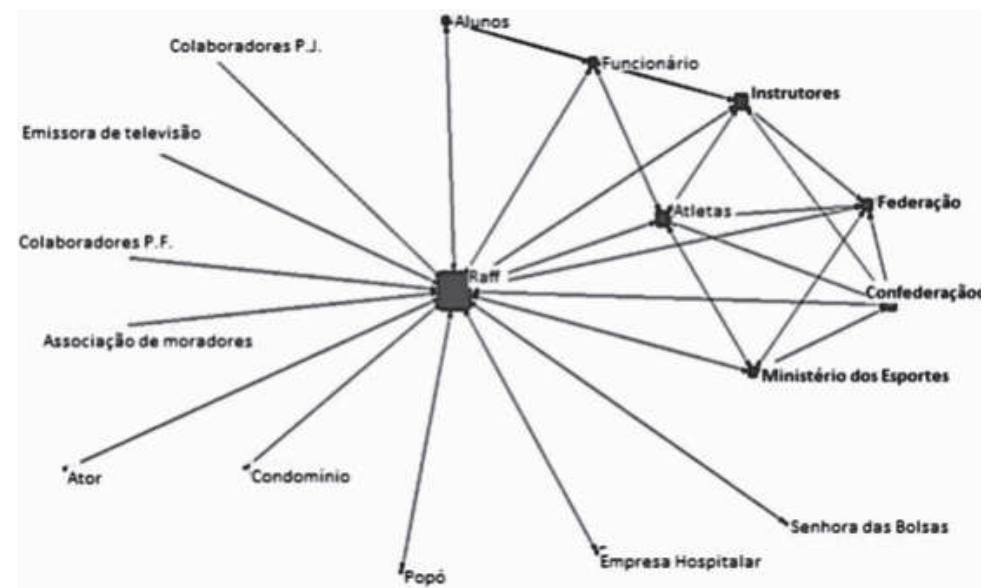

FIGURA 1 - Desenho da rede do Projeto Boxe Vidigal.

Grau de centralidade

Os parceiros mais atuantes estão próximos ao núcleo da rede. O ator principal é Raff Giglio. De fato, a rede só existe até o momento em funçáo de sua atuação. O QUADRO 1 mostra o grau de centralidade da rede. Constata-se que Raff Giglio é o ator central, tendo em vista ter vínculos com todos os atores da rede o que lhe propicia formas alternativas de satisfazer necessidades e, portanto, ser menos dependente de outros atores.

O grau de importância de Raff Giglio se expressa pelos graus de entrada e de saída (QUADRO 1). Raff possui 16.000 de grau de saída e também de entrada. $\mathrm{O}$ grau de centralização da rede, tanto de entrada como o de saída, é 83,594\%. O que mostra que a rede é por demais dependente da figura de Raff.

QUADRO 1-Medidas de centralidade de grau de Freeman.

\section{Quadro 1 - Medidas de Centralidade de Grau de Freeman}

$\begin{array}{lc}1 & \text { Raff } \\ 3 & \text { Atletas } \\ 5 & \text { Instrutores } \\ 6 & \text { Federação } \\ 7 & \text { Confederaçăo } \\ 4 & \text { Funcionários } \\ 8 & \text { Ministério do Esporte } \\ 2 & \text { Alunos } \\ 9 & \text { Empresa Hospitalar } \\ 10 & \text { Ator } \\ 11 & \text { Senhora das Bolsas } \\ 12 & \text { Popó } \\ 13 & \text { Condomínio } \\ 14 & \text { Associaçăo de Moradores } \\ 15 & \text { Colaboradores P.F. } \\ 16 & \text { Colaboradores P. J. } \\ 17 & \text { Emissora de Televisăo }\end{array}$

\begin{tabular}{|c|c|c|c|}
\hline $\begin{array}{c}1 \\
\text { OutDegree } \\
\text { (Grau de saida) }\end{array}$ & $\begin{array}{l}2 \\
\text { InDegree } \\
\text { (Grau de entrac }\end{array}$ & $\begin{array}{l}\quad 3 \\
\text { NrmoutDeg } \\
\text { da) (No grau de saída }\end{array}$ & $\begin{array}{l}4 \\
\quad \text { Nrm } \ln D e g \\
\text { a) (NNo grau de entrada) }\end{array}$ \\
\hline $\begin{array}{r}16.000 \\
6.000 \\
6.000 \\
5.000 \\
5.000 \\
4.000 \\
4.000 \\
3.000 \\
1.000 \\
1.000 \\
1.000 \\
1.000 \\
1.000 \\
1.000 \\
1.000 \\
1.000 \\
1.000\end{array}$ & $\begin{array}{r}16.000 \\
6.000 \\
6.000 \\
5.000 \\
5.000 \\
4.000 \\
4.000 \\
3.000 \\
1.000 \\
1.000 \\
1.000 \\
1.000 \\
1.000 \\
1.000 \\
1.000 \\
1.000 \\
1.000\end{array}$ & $\begin{array}{r}100.000 \\
37.500 \\
37.500 \\
31.250 \\
31.250 \\
25.000 \\
25.000 \\
18.750 \\
6.250 \\
6.250 \\
6.250 \\
6.250 \\
6.250 \\
6.250 \\
6.250 \\
6.250 \\
6.250\end{array}$ & $\begin{array}{r}100.000 \\
37.500 \\
37.500 \\
31.250 \\
31.250 \\
25.000 \\
25.000 \\
18.750 \\
6.250 \\
6.250 \\
6.250 \\
6.250 \\
6.250 \\
6.250 \\
6.250 \\
6.250 \\
6.250\end{array}$ \\
\hline avedas da & $\begin{array}{l}83.594 \% \\
83.594 \% \\
\text { aset Freemal }\end{array}$ & nDegree & \\
\hline
\end{tabular}

Densidade da rede

A densidade de uma rede é a quantidade de relações observadas pela quantidade total de relaçôes possíveis. O QUADRO 2 mostra que a densidade da rede analisada é de $21,32 \%$, ou seja, num total de $100 \%$ de possibilidades de relaçôes, tem-se $21,32 \%$ de relaçóes efetivadas. 
QUADRO 2 - Densidade da rede.

BLOCKDENSITIES OR AVERAGES
Density (matrix average) $=0.2132$
Standard deviation $=0.4096$
Use MATRIX>TRANSFORM DICHOT OMIZE procedure to get binary image matrix.
Density table(s) saved as dataset Density
Standard deviations saved as dataset DensitySD
Actor-by-actor pre-image matrix saved as dataset DensityModel
- Running time: 00:00:01
Output generated: 04 jan 11 19:48:17
UCINET 6.300 Copyright (c) 1992-2010 Analytic Technologies

\section{Entrevistas com o grupo focal}

Nesta parte, apresenta-se o resultado das entrevistas realizadas com os alunos, atletas e instrutores. Opera-se de forma a efetuar uma síntese do núcleo, da periferia e do que surgiu de forma incidental nas entrevistas.

De acordo com a metodologia utilizada, uma pergunta era proposta ao grupo, que espontaneamente se expressava, sem qualquer determinação de ordem de fala ou sequência. $O$ participante também poderia não responder as perguntas ou mesmo respondê-la em outro momento. As expressóes entre aspas são excertos das falas dos participantes. As categorias foram construídas a partir do núcleo das representaçóes. Este núcleo foi identificado a partir da ratificação e consenso construído em torno de ideias que foram surgindo durante a entrevista.

O boxe mudou a vida: educação, comportamento, perspectivas e agressividade

Para os alunos e atletas, as ideias apontam que o PBV exerce influência direta na inclusão social dos jovens na comunidade. Acreditam que a prática do boxe "mudou suas vidas". Os relatos mostram que o comportamento em casa e com os familiares "melhorou muito com a prática do boxe"; creditam à prática do boxe o fato de se "tornarem menos agressivos"; indicam que o projeto exerce uma "influência direta para a sua formação educacional". Demonstram que a "expectativa de futuro está ligada diretamente ao boxe”.

Os relatos mostram ainda, de forma periférica, que a "oportunidade de aprender um esporte" e "ocupar o tempo livre" são argumentos utilizados para justificar a importância atribuída ao PBV na inclusão social. Observa-se que a oportunidade de "botar para fora as tensões do dia a dia" é um dos fatores que levam os alunos a participar. Alguns dos participantes aduzem que a "oportunidade de estar com os amigos" e "fazer novas amizades" são considerados momentos de lazer. Alguns afirmam que a prática esportiva é uma “oportunidade para transformá-los em cidadãos”, justificando a importância do projeto.

De forma incidental, ou seja, apareceu de forma isolada nos relatos, mas não foi objeto de consenso, estão as ideias de "destrava", no sentido de que abre os olhos, a cabeça, isto é, amplia os horizontes. "Doutrina" é outro termo que aparece isolado em um dos discursos, no sentido de que o boxe trabalha ensinamentos que poderiam ser considerados como doutrina. "Manter a forma física" aparece em apenas uma das falas. Aparece também a ideia de "disciplina total". O termo é empregado por um aluno sugerindo que "disciplina" não deveria ser tão somente no PBV, mas em casa com familiares, amigos, escola etc. Apareceu também a expressão: "aqui é uma família”. O entrevistado utilizou o termo demonstrando acolhimento. Temos o termo "postura", ligado diretamente à educação. A frase "pessoas que cresceram comigo estão presas e outras estão mortas", deixando evidente que o boxe o tirou do caminho do crime.

\section{Melhora no rendimento escolar, mudança comportamental e perspectiva de vida}

Nas entrevistas realizadas com os instrutores, o núcleo das respostas foi formado pelas seguintes ideias: o PBV tem "grande responsabilidade na orientação das crianças e adolescentes contra o consumo de álcool, fumo e drogas". Os entrevistados percebem que a prática do boxe auxilia na "melhora do rendimento escolar", pois a orientação que recebem no projeto faz com que "melhorem o comportamento, o desenvolvimento e a inteligência, tornando-se mais dedicados aos estudos". Acreditam que a prática do "boxe mudou" e pode mudar ainda mais "a vida de seus alunos". Todos os instrutores entrevistados acreditam que exercem um bom papel 
na vida dos alunos e se "veem como exemplo para eles". Afirmam que o PBV "incentiva os alunos a participarem de outros projetos e atividades sociais existentes na comunidade".

De forma periférica, aparece nos relatos a possibilidade de "participar de campeonatos" e vir a "receber bolsa atleta" ou "se tornar instrutor do projeto". Estes são fatores importantes para os alunos que sonham em melhorar seu padráo de vida, segundo o ponto de vista dos instrutores. Percebe-se que a oportunidade de "amenizar a agressividade" é um dos fatores que leva os alunos a participarem do PBV.

De forma incidental está o termo "canalizar", no sentido de conduzir para um determinado objetivo, neste caso, o boxe. "Metodologia" é outro termo que aparece isolado em um dos discursos, no sentido de que o projeto tem regras e uma forma de ensino que deve ser respeitada.

\section{Entrevistas com os colaboradores}

Buscou-se ouvir também um colaborador (C1) e o representante da Confederação Brasileira de Boxe (C2). Destacamos os principais pontos em suas falas.

\section{Contribuição na formação social}

O colaborador $(\mathrm{C} 1)$ é pós-graduado em gestáo de pessoas, e atua no projeto desde 2002, como voluntário, ficou claro que a sua contribuição para o PBV está mais centrada no convívio e na troca de experiência com os alunos, pois os "vê como irmãos

\section{Discussão}

Em relação ao objetivo específico a) analisar as características da rede construída no PBV, os dados coletados apontam que esta rede pode ser classificada como interpessoal.

Por ser uma rede no campo interpessoal, com características também de uma rede de movimentos sociais, a informalidade prevalece sobre a formalidade, conforme indica a literatura consultada ${ }^{17-42}$. Grande interação pessoal se configura entre Raffi Giglio, Popó, a empresa de material hospitalar. As relaçóes formais se encontram mais na sinergia com os funcionários, instrutores e com o Ministério do Esporte.

Além das relaçôes serem mais informais do que formais, a rede se caracteriza pelos interesses e valores comuns, troca/ajuda mútua e confiança/cumplicidade, mais novos". Ele também contribui materialmente, com auxílios financeiros.

Tem consciência de que o objetivo principal do PBV é "contribuir na formação social das crianças e jovens através do boxe", pois os "benefícios que este esporte proporciona atingem também as famílias".

Entende que muitos alunos que passaram pelo projeto não seguiram a carreira de lutador, mas "ficaram conhecimentos adquiridos para toda a vida".

Afirma que o PBV "é muito bem visto pela comunidade por ser um projeto sério e respeitado". Além disso, tem convicção de que "cada comunidade deveria ter pelo menos um projeto como o PBV, voltado para o esporte e cultura, ocupando o tempo de crianças e jovens com uma atividade esportiva".

\section{Inclusão social e ocupação do tempo}

As respostas do supervisor nacional de boxe da Confederação Brasileira de Boxe (C2), apontam que "o boxe e o atletismo são esportes que têm proporcionado a inclusão social de pessoas que vivem em comunidades pobres". Considera "fundamental os jovens ocuparem parte do tempo praticando esportes". Para C2, "a comunidade está envolvida com o projeto e o legitima".

A atuação da Confederaçáo Brasileira de Boxe junto ao projeto "se dá de forma indireta. Cabe a ela organizar e supervisionar eventos, tanto no Rio de Janeiro como em outros Estados". Os atletas do PBV participam dos campeonatos estaduais e do campeonato brasileiro que são supervisionados pela entidade. expressos principalmente nas relações de Raff com os alunos, atletas, Popó, instrutores e funcionários.

Há também engajamento expresso nas relaçôes do projeto com a empresa de material hospitalar, o ator de televisáo, uma colaboradora que fornece cestas básicas e o condomínio, que foi um espaço inicial que permitiu o desenvolvimento do projeto.

A rede apresenta baixa densidade, o que indica encontrar-se em processo de fortalecimento, com pouco potencial ainda para exercer maior poder. Esta baixa densidade pode ser um fator que futuramente impacte de forma negativa na sua expansão. Seria importante que o número de relaçóes possíveis fosse aumentado e também a preparaçáo de novas lideranças nos setores ou nós da rede. 
A legitimidade e visibilidade que o projeto conquistou até hoje são indicadores nítidos de um trabalho que tem impacto na comunidade. A rede que vem sendo construída tende a se expandir, principalmente, em função da capacidade de seu ator principal em captar recursos e participaçóes voluntárias.

Os relatos apontam que a característica principal da rede PBV prende-se à racionalidade comunicativa, entendida como substantiva, onde há prevalência dos valores, do respeito pelo outro, sobre a racionalidade instrumental, onde o principal se dá na relação custo/benefício, no lucro, e na técnica ${ }^{17}$.

Verifica-se grande centralização das açōes na pessoa do idealizador do projeto, por esta razão há baixa densidade e alta centralidade na rede.

Em relação ao objetivo específico b) interpretar as representações de membros da rede sobre os sentidos e significados atribuídos ao projeto na comunidade do Vidigal, os relatos mostram que os participantes convivem com a violência, mas destacaram que a prática do boxe possui potencial para desestimular o uso de drogas e a participação em atos de delinquência. Neste sentido, reafirma-se a importância da prática não só do boxe, mas de todas as modalidades esportivas.

O núcleo das representaçóes reside na ideia da capacidade de mudança, transformação social do PBV. Mudança de vida, melhora no rendimento escolar, mudança de comportamento, menos agressividade, educação, perspectiva de vida, formação social, inclusão social e ocupação do tempo, são representaçóes que se destacam e formam o núcleo. Além deste núcleo, compóem a periferia das representaçóes as seguintes ideias: oportunidade de estar com os amigos, fazer novas amizades, colocar as tensóes para fora, tornar-se instrutor, participar de competiçôes, lazer, cidadania e ganhar bolsa atleta.

A identificação deste núcleo e periferia ratifica em parte o que Castro e Souza ${ }^{43}$ encontraram em sua pesquisa sobre significados atribuídos a um projeto esportivo social. Sua conclusão aponta que o projeto protege os jovens de "males das ruas", e se apresenta como um espaço de aprendizagem, de jogar, brincar, e se divertir com os amigos. Em certo sentido, as conclusóes de Castro e Souza perpassam também os relatos dos sujeitos entrevistados neste trabalho. Os participantes relataram que adquiriram conhecimentos sociais que são gerados pela prática do boxe, bem como a oportunidade de fazer novas amizades e desfrutarem de um espaço de lazer.

No entanto, a ênfase na melhoria do rendimento escolar, a perspectiva de futuro a partir do boxe, a intenção de se tornarem instrutores, a influência na formação social e comportamento da própria família, são significados que se destacam neste estudo.

MARQUES $^{44}$ constata a contribuição do esporte para a melhoria do autoconceito da pessoa, náo apenas no que concerne à dimensão motora, mas também em outros aspectos do desenvolvimento humano. Pode-se perceber que os relatos dos jovens entrevistados neste estudo ratificam as conclusóes de Marques. Para este autor, um projeto esportivo social náo deve focalizar apenas a dimensão motora; a prioridade das instituiçôes que se dedicam aos projetos esportivos sociais deve ser a formação social de seus participantes. Nossa constatação é a de que o PBV enfatiza os aspectos substantivos e não apenas os instrumentais.

O Projeto Boxe Vidigal apresenta grande potencial no seu desenvolvimento, leva benefícios à comunidade, principalmente pela carência de recursos, e representa um espaço gratuito de lazer, com estímulo à promoçáo da saúde e responsabilidade.

A legitimidade e visibilidade que o projeto conquistou até hoje são indicadores nítidos de um trabalho que tem impacto na comunidade. A rede que vem sendo construída tende a se expandir, principalmente, em função da capacidade de seu ator principal em captar recursos e participaçôes voluntárias.

Sugere-se que se efetive uma aproximaçáo dessa rede com alguma universidade, de forma a ampliar as possibilidades de crescimento e sistematizaçáo do conhecimento tácito desenvolvido pelos atores do projeto. A universidade também poderia auxiliar em questôes relativas a legislações de incentivo ao esporte, elaboração de um site pela área de comunicação, mapeamento de processos, análise dos pontos fortes e fracos, análise de oportunidades e ameaças, entre outras açōes possíveis.

Existem doadores esporádicos que ajudam a sanar alguns problemas no projeto, porém, é visível a necessidade de novos atores na composição da rede que possam contribuir e oferecer condiçóes para a melhor funcionalidade.

Ficou explícito que a utilização do boxe facilita a integração e o relacionamento interpessoal entre crianças e adolescentes com suas famílias. O interesse pelo esporte estreita os laços afetivos entre as pessoas proporcionando-lhes maior poder de indução em sua rede social.

Tentamos tecer, neste estudo, uma análise que buscasse uma aproximação entre a visão da estrutura, na dimensão macro, com a visão dos participantes da rede (coordenador, alunos, atletas, colaboradores). Ao constatarmos a grande centralidade da rede na pessoa de seu idealizador e coordenador, e 
alcançarmos isto por via de uma análise macro, tal fato não impossibilitou que as representaçôes dos atores, na dimensão micro, de que o PBV exerce grande influência na comunidade, sendo capaz de mudar vidas, fossem utilizadas em conjunto para fazer algumas inferências, tais como: um dos pontos fortes do PBV é o grande impacto que exerce nos aspectos comportamentais dos jovens da comunidade, dando-lhes sentido para construírem perspectivas de futuro. Entretanto, a grande concentração das açóes na pessoa de seu idealizador e coordenador pode, no futuro, inviabilizar o próprio projeto pela falta de novas lideranças que venha a compartilhar com o idealizador o crescimento do projeto. Assim temos um ponto forte que gera oportunidades e um ponto fraco que pode gerar ameaças.

\begin{abstract}
Network design of a social sports project: actors, representations and meanings

This study is offered with the aim of exploring the meanings assigned by a network of actors who develops a social sports project. The Boxing Project Vidigal (PBV) has its activities in the Vidigal slum, located in the south of the city of Rio de Janeiro, next to the neighborhood of Leblon. The methodology used in this study was based on the procedures of network analysis and also the construction of categories, based on the definition of the core and the periphery of representations. We conclude that there is great centralization of the person who conceived the project, for this reason there is low density and high centrality in the network. The perceptions of the actors roam the ideas that the project "changes people's lives," that young people "become less aggressive," that there are "social contribution in the formation of children, youth and families" and promotes "social inclusion of people living in poor.
\end{abstract}

KEY wORDS: Social sports project; Physical education; Child; Sport.

\title{
Referências
}

1. Bretâs A. Onde mora o perigo? Discutindo uma suposta relação entre ociosidade, pobreza e criminalidade. Educação, esporte e lazer. [citado 10 fev. 2011]. Disponível em: http://www.tvebrasil.com.br/salto/boletins2007/eel/070611_educacaoesporte.doc.

2. Guedes SL, Davies JA, Rodrigues MA, Santos RM. Projetos sociais esportivos: notas de pesquisa. XII Encontro Regional de História; 2006; Niterói, BR. Rio de Janeiro: ANPUH; 2006. p.92.

3. Melo MP. Lazer, esporte e cidadania: debatendo a nova moda do momento. Movimento. 2004:10:105-22.

4. Melo MP. Esporte e juventude pobre: políticas públicas de lazer na Vila Olímpica da Maré. Campinas: Autores Associados; 2005.

5.Altieri MA, Másera O. Desenvolvimento rural sustentável na América Latina: construindo de baixo para cima - reconstruindo a agricultura: ideias e ideais na perspectiva do desenvolvimento rural sustentável. Porto Alegre: Universidade/ UFRGS; 1997.

6. Turino C. Ponto de cultura: o Brasil de baixo para cima. [citado 20 fev. 2011]. Disponível em: http://www.youtube. $\mathrm{com} /$ watch? $=$ YY3kgncXPPk.

7. Santos BS. Uma concepção multicultural de direitos humanos. Lua Nova. 1997:39:111. Disponível em: http://www. scielo.br/scielo.php?script=sci_arttext\&pid=S0102-64451997000100007\&lng=en\&nrm=iso.

8. Zaluar A. Cidadãos não vão ao paraíso. São Paulo: Escuta; 1994.

9. Thomassim LEC. Uma alternativa metodológica para a análise dos projetos sociais esportivos. XVIII Encontro Nacional de Recreação e Lazer; 2006; Curitiba, BR. Curitiba: PUCPR; 2006.

10. Silveira J. Desenvolvimento humano, responsabilidade social e educação no capitalismo: investigando o programa "Educaçáo pelo Esporte" do Instituto Ayrton Senna [dissertação]. Florianópolis (SC): Universidade Federal de Santa Catarina; 2007. 
11. Silva CAF, Terra B, Votre SJ. O modelo da hélice tríplice e o papel da educação física, do esporte e do lazer no desenvolvimento local. Rev Bras Ciên Esporte. 2006;28:167-83.

12. Marques RFR, Almeida MAB, Gutierrez GL. Esporte: um fenômeno heterogêneo, estudo sobre o esporte e suas manifestações na sociedade contemporânea. Movimento. 2007;13:225-42.

13. Murad M. A violência e o futebol: dos estudos clássicos aos dias de hoje. Rio de Janeiro: Editora FGV; 2007.

14. Mizruchi MS. Análise de redes sociais: avanços recentes e controvérsias atuais. Rev Adm Emp. 2006;46:72-86.

15. Kimura H, Teixeira MLM, Godoy AS. Redes sociais, valores e competências: simulação de conexóes. Rev Adm Emp. 2006;46:42-57.

16. Morin E. Introdução ao pensamento complexo. Porto Alegre: Sulina; 2006.

17. Marteleto RM. Análise de redes sociais: aplicação nos estudos de transferência da informação. Ci Inf. 2001;30:71.

18. Lipnack J, Stamps J. Networks: redes de conexôes. São Paulo: Aquariana; 1992.

19. Wasserman S, Faust K. Social network analysis: methods and applications. Cambridge: Cambridge University Press; 1999.

20. Freitas MC, Pereira HBB. Contribuição da análise de redes sociais para o estudo sobre os fluxos de informaçôes e conhecimento. VI Encontro Nacional de Ensino e Pesquisa da Informação; 2005; Salvador, BR. Salvador; 2005.

21. Lago MWL. Redes sociais informais intraorganizacionais e os processos de mudança organizacionais: estudo em uma empresa de tecnologia da informação [dissertação]. Salvador (BA): Universidade Federal da Bahia; 2005.

22. Regis HP, Bastos AVB, Dias SMRC. Redes sociais informais: análise das redes de amizade, de informação e de confiança em incubadora de base tecnológica no Recife. Rev Psicol. 2007;7:31-56.

23. Silva MC. Rede sociais intraorganizacionais informais e gestão: um estudo nas áreas de manutenção e operação da planta Hyco-8, Camaçari [dissertação]. Salvador (BA): Universidade Federal da Bahia; 2003.

24. Santos MV. Redes sociais informais e compartilhamento de significados sobre mudança organizacional: estudo numa empresa petroquímica [dissertação]. Salvador (BA): Universidade Federal da Bahia; 2004.

25. Macambira MO. Comprometimento organizacional e redes sociais informais: a estrutura das relaçóes interpessoais e o vínculo com a organização [dissertação]. Salvador (BA): Universidade Federal da Bahia; 2009.

26. Junqueira L. Descetralización, intersectorialidad y red en la gestión de la ciudad: reforma y democracia. Rev CLAD. 1998;12: 89-108.

27. Inojosa RM. Redes e redes sociais. São Paulo: FUNDAP; 1998.

28. Loiola E, Moura S. Análise de redes: uma contribuição aos estudos organizacionais. In: Fischer T. Gestão contemporânea: cidades estratégicas e organizaçóes locais. Rio de Janeiro: FGV, 1996. p.53-68.

29. Packman M. Redes: una metáfora para práctica de intervención social. In: Dabas E., Najmanovick D, organizadores. Redes: el lenguage de los vínculos. Buenos Aires: Paidós; 1995. p.294-302.

30. Etzkowitz H. Hélice tríplice - universidade-indústria-governo: inovação em movimento. Porto Alegre: EDIPUCRS; 2009.

31. Borgatti SP, Everett MG, Freeman LC. Ucinet for windows: software for social network analysis. Harvard: Analytic Technologies; 2002.

32. Abric, JC. A abordagem estrutural das representações sociais. In: Moreira ASP, Oliveira DC. Estudos interdisciplinares de representação social. Goiania: AB; 1998.

33. Abric JC. Pratiques sociales et représentations. Paris: Lavoisier; 2003.

34. Abric JC. La recherche du noyau central et de la zone muette des représentations sociales. In: Abric JC. Méthodes d'étude des représentations sociales. Paris: Eres; 2003.

35. Devide FP. Teoria das representaçóes sociais, análise do discurso e etnometodologia: contribuiçóes para a pesquisa da educação física. In: Silva CAF, Votre SJ. Etnometodologias. Rio de Janeiro: HP Comunicação; 2012.

36. Denzin NK, Lincoln YS. Handbook of qualitative research. Tousand Oaks: Sage; 1994.

37. Champagne F, Potvin L, Denis JL, Boyle P. Saber preparar uma pesquisa. São Paulo: Hucitec Abrasco; 1997.

38. Thomas JR, Nelson JK, Silverman SJ. Métodos de pesquisa em atividade física. Porto Alegre: ArtMed; 2007.

39. Bauer M, Gaskell G. Pesquisa qualitativa com texto, imagem e som: um manual prático. Petrópolis: Vozes; 2004.

40. Mazzotti AJ, Gewandsznajder F. O método nas ciências naturais e sociais. São Paulo: Thompson; 2002.

41. Negrine A. Instrumentos de coleta de informaçóes na pesquisa qualitativa. In: Neto VM, Triviños ANS. A pesquisa qualitativa na educação física: alternativas metodológicas. Porto Alegre: Sulina; 1999. p.61-93.

42. Minhoto LD, Martins CE. As redes e o desenvolvimento social. Cad FUNDAP. 2001:22:81-101.

43. Castro SBE, Souza DL. Significados de um projeto social esportivo: um estudo a partir das perspectivas de profissionais, pais, crianças e adolescentes. Movimento. 2011:17:145-63.

44. Marques ERD. Projetos sociais esportivos: um estudo das relaçôes entre o esporte e o autoconceito [dissertação]. São Paulo (SP): Universidade de São Paulo, Escola de Educação Física e Esporte; 2012. 
Silva OM \& Silva CAF.

Carlos Alberto Figueiredo da Silva

Universidade Salgado de Oliveira

R. Marechal Deodoro, 263

24030-06o - Niterói - RJ - BRASIL

e-mail: ca.figueiredo@yahoo.com.br
Recebido para publicação: 05/04/2013

1a. Revisão: 01/08/2013

2a. Revisão: 18/11/2013

3a. Revisão: 28/02/2014

Aceito: 03/03/2014

428 • Rev Bras Educ Fís Esporte, (São Paulo) 2014 Jul-Set; 28(3):415-28 